\title{
COMPARING THE EFFECT OF TOTAL SOLIDS CONCENTRATION ON BIO- HYDROGEN PRODUCTION POTENTIAL OF FOOD WASTE AND ITS DERIVATIVES UNDER MESOPHILIC THERMOPHILIC CONDITIONS
}

\author{
Chaudhry Arslan 1,2, , Asma Sattar', , Ji Changying, ${ }^{1, *}$, Abdul Nasir², Irshad Ali Mari ${ }^{3}$, Fang \\ Huimin ${ }^{1}$ and Huang Yu Ping ${ }^{1}$
}

\author{
${ }^{1}$ College of Engineering, Nanjing Agricultural University, Nanjing, Jiangsu 210031, China; \\ ${ }^{2}$ Department of Structures and Environmental Engineering, University of Agriculture Faisalabad, Pakistan; \\ ${ }^{3}$ Khairpur College of Agricultural Engineering and Technology, Sindh Agricultural University, Tandojam, Pakistan. \\ "Corresponding author’s e-mail: chyji@njau.edu.cn, arslanakrampk@ hotmail.com
}

\begin{abstract}
The effect of three total solid (TS) concentrations of 7.5, 10 and 12.5\% on bio-hydrogen production potential of food waste $(\mathrm{FW})$ in comparison with noodle waste $(\mathrm{NW})$ and rice waste $(\mathrm{RW})$ derived from $\mathrm{FW}$ were studied after co-digesting the wastes with heat shocked sludge under mesophilic $\left(37^{\circ} \mathrm{C}\right)$ and thermophilic $\left(55^{\circ} \mathrm{C}\right)$ conditions. The increase in TS concentration from $7.5 \%$ to $10 \%$ found an effective way to improve cumulative bio-hydrogen production from all tested wastes. As a whole, $7.5 \%$ TS concentration represented higher conversion efficiency of volatile solids into bio-hydrogen and the highest experimental yield of $95.8 \mathrm{~mL} / \mathrm{VS}_{\text {fed }}$ was observed in $7.5 \% \mathrm{NW}$ digester under thermophilic conditions. The increase in temperature within experimental range found an effective way to increase bio-hydrogen production potential of FW and NW only, whereas the same increase in temperature caused negative impact on bio-hydrogen production potential of RW. The optimum time period for active bio-hydrogen production found to be $24-72 \mathrm{~h}$ of incubation. After $72 \mathrm{~h}$ of incubation, the bio-hydrogen production reduced considerably in all reactors due to an abrupt increase in volatile fatty acid, and due to inhibition of bio-hydrogen production the drop in $\mathrm{pH}$ was also decreased.
\end{abstract}

Keywords: Bio-hydrogen yield, total solids concentration, Clostridium, rice waste, noodles waste, volatile fatty acids.

\section{INTRODUCTION}

Hydrogen is a promising source of energy $(122 \mathrm{~kJ} / \mathrm{g})$ with zero pollutant emission as no greenhouse gases are produced during combustion of hydrogen which make it a suitable alternate to fossil fuels (Pisutpaisal and Hoasagul, 2012). Conventionally the hydrogen is produced by electrochemical or thermochemical processes that consume a lot of energy and are not environment friendly (Chen et al., 2006) . On the other end, the most common biological mean of bio-hydrogen production is anaerobic digestion and the hydrogen produced by anaerobic digestion is often termed as bio-hydrogen. The anaerobic digestion can utilize a mixed consortia of Clostridium in the form of sludge as an optimum source of microbial culture because it contains 64 to $70 \%$ Clostridium as well as it has some nutrients which are important for biohydrogen production processes (Fang et al., 2006; Liaquat et al., 2015). Along with Clostridium, sludge also contains hydrogen consumers like methanogens which can be initial deactivated by pretreatment like heat shock etc.

The microorganisms require some source of carbohydrates as feedstock to produce bio-hydrogen during anaerobic digestion. Although a variety of feedstocks like lignocellulosic and carbohydrate based wastes can be utilized for this purpose but carbohydrate based wastes are more preferable because they do not need intensive pretreatment to release sugar content entangled by lignin binding (Sattar $e t$ $a l ., 2016)$. In this regard, food waste (FW) or organic fraction of municipal solid waste (OFMSW) is getting now widely tested for bio-hydrogen production as it is abundantly available on daily basis and the managerial issues are also resolved by anaerobic digestion (Fountoulakis and Manios, 2009). The FW has 50 to $70 \%$ share in municipal solid waste (MSW) generated in China where major contributor to food waste are canteens as $28.3 \%$ of the ordered food ends up in the waste bin (Tai et al., 2011). About $40 \%$ of FW is composed of noodle waste (NW) and rice waste (RW) (Shiwei, 2005; Wang Lingen et al., 2013). In order to digest FW under anaerobic conditions, microorganisms required optimum operational conditions like $\mathrm{pH}$ and temperature (Saraphirom and Reungsang, 2010). Normally, FW has a low $\mathrm{pH}$ of 4-5 which would be further reduced during anaerobic digestion due to production of volatile fatty acids (VFA). If the process $\mathrm{pH}$ is lowered than $\mathrm{pH} 4$, it can affect metabolic pathways which ultimately inhibit the activity of biohydrogen producing bacteria (Morimoto et al., 2004; Fang et al., 2006). On the other end, increasing process $\mathrm{pH}$ from $\mathrm{pH}$ 7 to $\mathrm{pH} 8$ also decreased the bio-hydrogen production (Lin et al., 2013; Nathao et al., 2013). Keeping in view these facts, the optimum $\mathrm{pH}$ range for bio-hydrogen production was 
found to be between $\mathrm{pH} 4.5$ to $\mathrm{pH} 8.5$ (Mizuno O, 2000). Apart $\mathrm{pH}$, process temperature is also an important operational parameter. The bio-hydrogen production can be done under psychrophilic conditions but it required specific chamber like microbial electrolysis cells which make the process complication Lu et al. (2011). So most of the research on bio-hydrogen production was conducted under mesophilic and thermophilic conditions ( $\mathrm{Li}$ and Liu, 2012; Saripan and Reungsang, 2014).

Along with $\mathrm{pH}$ and temperature, dry matter content or total solids (TS) is a crucial factor that can affect the anaerobic digestion. Increasing the TS concentration will reduced the reactor size but it can also reduce the bio-hydrogen yield due to osmotic stress, high metabolite accumulation that ultimately cause microbial inhabitation (Robledo-Narvaez et $a l ., 2013)$. Keeping in view these facts, most of the biohydrogen production through anaerobic digestion was done under liquid state conditions with TS concentration less than 15\% (Nabi et al., 2003) . The impact of increasing TS concentration under liquid state anaerobic digestion is also an important factor which was tested under 1 to $9 \%$ TS concentration under similar set of experiments resulting $9 \%$ TS concentration as an optimum TS for bio-hydrogen production from food waste (Ramos et al., 2012). Still the TS concentration can be further increased till the variable maximum concentration achieved. Therefore, the objective of following research was to study the effect of initial total solids on bio-hydrogen production from co-digestion of food waste and its derivatives with heat shocked sludge under mesophilic and thermophilic temperature conditions.

\section{MATERIALS AND METHODS}

Feedstock preparation: The FW was collected from canteen at the Engineering College, Nanjing Agricultural University, Nanjing, China. It was mainly made up by rice, noodles, meat and vegetables. At first bones and other unwanted materials were removed and left over waste was termed as FW. Later the FW was grounded in a meat grinder by adding an equal amount of water on weight basis and resultant slurry was used for bio-hydrogen production (Reungsang et al., 2013). The RW and NW were also separated manually from the waste collected from the canteen and converted into slurry in the same way opted for FW.

The sludge was obtained from a wastewater settling channel at Pukou, Nanjing. Foreign materials and coarse particles (diameter $>0.5 \mathrm{~mm}$ ) were removed by sieving and washed it twice with tap water (Nathao et al., 2013). Later it was placed in preheated oven at $100^{\circ} \mathrm{C}$ for 15 minutes to deactivate methanogens (Li and Fang, 2007). Some properties of waste used in the experiments are enlisted in Table 1.

Table 1. Properties of test materials.

\begin{tabular}{lccccc}
\hline Parameter & Unit & Sludge & $\begin{array}{c}\text { Food } \\
\text { waste }\end{array}$ & $\begin{array}{c}\text { Rice } \\
\text { waste }\end{array}$ & $\begin{array}{c}\text { Noodle } \\
\text { s waste }\end{array}$ \\
\hline TS & $\%$ & 58.59 & 30.32 & 39.88 & 31.54 \\
VS & $\%$ & 2.87 & 26.9 & 39.30 & 28.51 \\
Glucose & $\mathrm{g} / \mathrm{L}$ & 2.49 & 65.77 & 79.65 & 63.73 \\
COD & $\mathrm{g} / \mathrm{L}$ & 50 & 147.5 & 105 & 132 \\
Total Alkalinity & $\mathrm{mg} / \mathrm{L}$ & 3700 & 550 & 500 & 450 \\
VFA (mg/L) & $\mathrm{mg} / \mathrm{L}$ & 13950 & 2475 & 9000 & 1500 \\
pH & --- & 7.1 & 4.5 & 5.3 & 4.3 \\
\hline
\end{tabular}

Experimental design: The FW was added in equal proportion on TS basis with heat shocked sludge in $550 \mathrm{~mL}$ lab scale digester after which water was added in such quantity to achieve the working volume of $400 \mathrm{~mL}$. Three initial TS concentration of $7.5 \%, 10 \%$ and $12.5 \%$ were maintained in six digesters, two for each TS concentration. These reactors were placed in two water baths; one at mesophilic temperature $\left(37 \pm 0.1^{\circ} \mathrm{C}\right)$ and other at thermophilic temperature $\left(55 \pm 0.1^{\circ} \mathrm{C}\right)$. Two sets of experiments (in duplicate) were performed (Zhu et al., 2008; Dong et al., 2009). Similar procedure was opted for NW and RW. The schematic diagram of experimental layout is shown in Figure 1. The $\mathrm{pH}$ of all reactors was maintained to a value of 7 after every 24 hours.

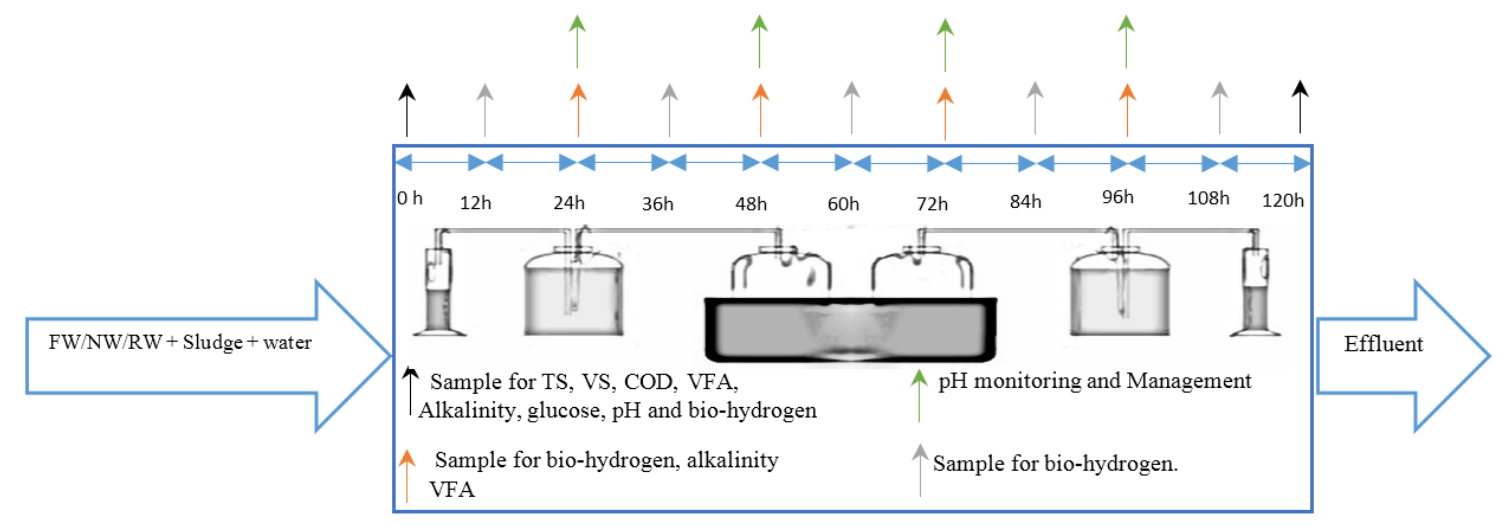

Figure 1. Schematic diagram of experimental setup.

Incubation under $37 / 55^{\circ} \mathrm{C}$ 
Samples collected before and during the experiment were stored in the refrigerator $\left(0-4^{\circ} \mathrm{C}\right)$.

Analytic methods and kinetic modeling: The bio-hydrogen production volume was measured by connecting each reactor with a measuring bottle containing $3 \% \mathrm{NaOH}$ solution as followed in our previous work (Chaudhry et al., 2015; Sattar et al., 2016). The TS, volatile solids (VS), Chemical oxygen demand (COD), alkalinity and volatile fatty acids were measured according to standard methods (APHA, 2005). Glucose was measured by the Phenol Sulfuric acid method (Lay and Fan, 2003). For TS, VS and COD, samples were taken before and after incubation, whereas for VFA and glucose, samples were taken with glass syringe after every twenty-four hours (Sreela-Or et al., 2011).

The kinetic parameters of bio-hydrogen production were calculated by the modified Gompertz equation using cumulative bio-hydrogen data (Dong et al., 2009; Ramos et al., 2012).

$$
\mathrm{H}=\operatorname{Pexp}\left\{-\exp \left[\frac{\mathbf{R}_{\mathrm{m}}^{\mathrm{e}}}{\mathbf{p}}(\lambda-\mathbf{t})+1\right]\right\}
$$

Where $\mathrm{H}, \mathrm{t}, \mathrm{P}, \mathrm{Rm}$, and e represent cumulative hydrogen production $(\mathrm{mL})$, incubation time $(\mathrm{h})$, hydrogen production potential, maximum hydrogen production rate $(\mathrm{mL} / \mathrm{h})$, lag phase duration (h) and 2.72, respectively. The equation was solved by using Matlab (ver. 2010 a).

In order to assess the effect of TS concentration, the yield was calculated by dividing the $\mathrm{P}$ value with volatile solids added (Liu et al., 2013).

\section{RESULTS AND DISCUSSION}

Effect of TS concentration on bio-hydrogen production: The effect of increase in TS concentration and shifting the temperature from mesophilic to thermophilic was different on different type of waste as shown in Figure 2. It can be observed from Figure 2 that the FW digester with $7.5 \%$ TS concentration has the higher cumulative bio-hydrogen production as compared to other two FW digester under mesophilic conditions. It is due to shorter lag phase $(\lambda)$ of $7.5 \% \mathrm{FW}$ (Table 2) as compared to other two digesters under mesophilic conditions, which caused an early start in biohydrogen production (Fig. 2a). The increase in TS concertation of FW decreased the cumulative bio hydrogen production under mesophilic condition due late start in production of bio-hydrogen due to high $\lambda$ value (Table 2, Fig. $2 \mathrm{a})$. Although the $\lambda$ for $12.5 \% \mathrm{FW}$ was smaller than $\lambda$ for $10 \% \mathrm{FW}$ i.e., $24.1 \mathrm{~h}$ at $10 \%$ and $21.54 \mathrm{~h}$ at $12.5 \%$, but still the cumulative bio-hydrogen production of $12.5 \% \mathrm{FW}$ TS was smaller than $10 \% \mathrm{FW}$ under mesophilic conditions. It was because of higher hydrogen production rate $\left(\mathrm{R}_{\mathrm{m}}\right)$ of $10 \% \mathrm{FW}$ as compared to $12.5 \% \mathrm{FW}$ under mesophilic conditions (Table 2). The increase in temperature from 37 to $55^{\circ} \mathrm{C}$ also increased the bio-hydrogen production. At the same time, the increase in FW TS concentration also increased cumulative bio-hydrogen production under thermophilic conditions, which was quit opposite to the effect observed under mesophilic conditions. This increase is due to Thermoanaerobacterium thermosaccharolyticum that grows at higher temperature in food waste and produced more hydrogen (Shin et al., 2004).

In case of NW, the increase in TS from 7.5 to $10 \%$ increased the bio-hydrogen production but further increase in TS concentration to $12.5 \%$ decreased the cumulative biohydrogen production under both tested temperatures (Fig. 2b). Although, increase in NW TS concentration reduced $\lambda$ but it also affects the $\mathrm{R}_{\mathrm{m}}$ which was higher for $10 \%$ (Table 2 ).

Table 2. Kinetic parameters and bio-hydrogen yield.

\begin{tabular}{|c|c|c|c|c|c|c|c|}
\hline Waste Type & TS (\%) & Temperature & $\mathbf{P}(\mathbf{m L})$ & $\mathbf{R}_{\mathrm{m}}(\mathrm{mL} / \mathrm{h})$ & $\lambda(\mathbf{h})$ & $\mathbf{R}^{2}$ & Bio-hydrogen yield (mL/VS fed) \\
\hline \multirow[t]{6}{*}{ Food waste } & \multirow[t]{2}{*}{7.5} & $37^{\circ} \mathrm{C}$ & 517.80 & 21.77 & 10.38 & 0.9960 & 36.90 \\
\hline & & $55^{\circ} \mathrm{C}$ & 845.00 & 14.49 & 6.48 & 0.9890 & 60.22 \\
\hline & \multirow[t]{2}{*}{10} & $37^{\circ} \mathrm{C}$ & 490.10 & 13.34 & 24.10 & 0.9969 & 27.05 \\
\hline & & $55^{\circ} \mathrm{C}$ & 981.20 & 10.09 & 3.23 & 0.9885 & 54.15 \\
\hline & \multirow[t]{2}{*}{12.5} & $37^{\circ} \mathrm{C}$ & 280.40 & 6.18 & 21.54 & 0.9911 & 12.20 \\
\hline & & $55^{\circ} \mathrm{C}$ & 1124.00 & 17.98 & 1.10 & 0.9833 & 48.91 \\
\hline \multirow{6}{*}{$\begin{array}{l}\text { Noodles } \\
\text { waste }\end{array}$} & \multirow[t]{2}{*}{7.5} & $37^{\circ} \mathrm{C}$ & 663.80 & 18.84 & 11.74 & 0.9890 & 46.42 \\
\hline & & $55^{\circ} \mathrm{C}$ & 1370.00 & 21.38 & 13.16 & 0.9870 & 95.80 \\
\hline & \multirow[t]{2}{*}{10} & $37^{\circ} \mathrm{C}$ & 1193.00 & 43.08 & 9.32 & 0.9910 & 62.75 \\
\hline & & $55^{\circ} \mathrm{C}$ & 1723.00 & 25.56 & 8.56 & 0.9820 & 90.64 \\
\hline & \multirow[t]{2}{*}{12.5} & $37^{\circ} \mathrm{C}$ & 832.70 & 13.13 & 5.65 & 0.9920 & 34.82 \\
\hline & & $55^{\circ} \mathrm{C}$ & 599.20 & 54.58 & 0.46 & 0.9725 & 25.07 \\
\hline \multirow[t]{6}{*}{ Rice waste } & \multirow[t]{2}{*}{7.5} & $37^{\circ} \mathrm{C}$ & 660.00 & 15.02 & 1.24 & 0.9889 & 41.22 \\
\hline & & $55^{\circ} \mathrm{C}$ & 82.02 & 2.47 & 28.99 & 0.9924 & 5.46 \\
\hline & \multirow[t]{2}{*}{10} & $37^{\circ} \mathrm{C}$ & 876.00 & 23.62 & 31.31 & 0.9819 & 42.52 \\
\hline & & $55^{\circ} \mathrm{C}$ & 122.90 & 4.25 & 35.02 & 0.9897 & 5.97 \\
\hline & \multirow[t]{2}{*}{12.5} & $37^{\circ} \mathrm{C}$ & 270.90 & 5.36 & 21.60 & 0.9496 & 10.46 \\
\hline & & $55^{\circ} \mathrm{C}$ & 357.60 & 11.70 & 24.27 & 0.9905 & 13.81 \\
\hline
\end{tabular}




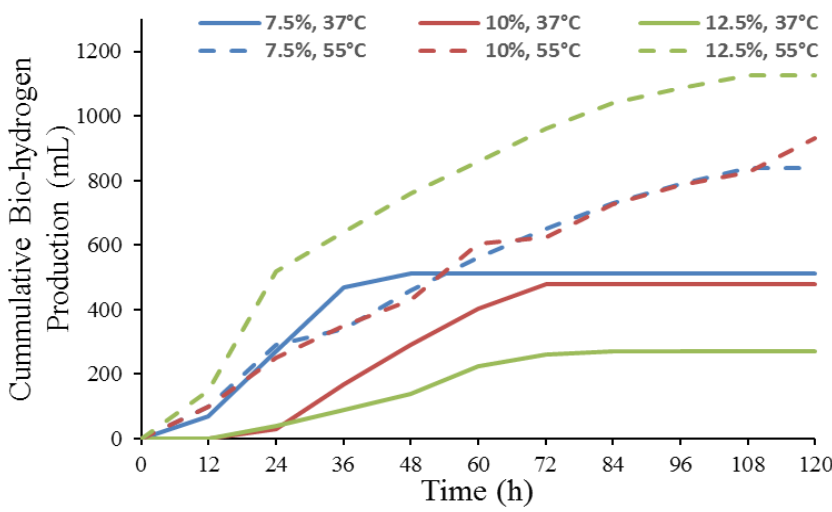

(a) FW

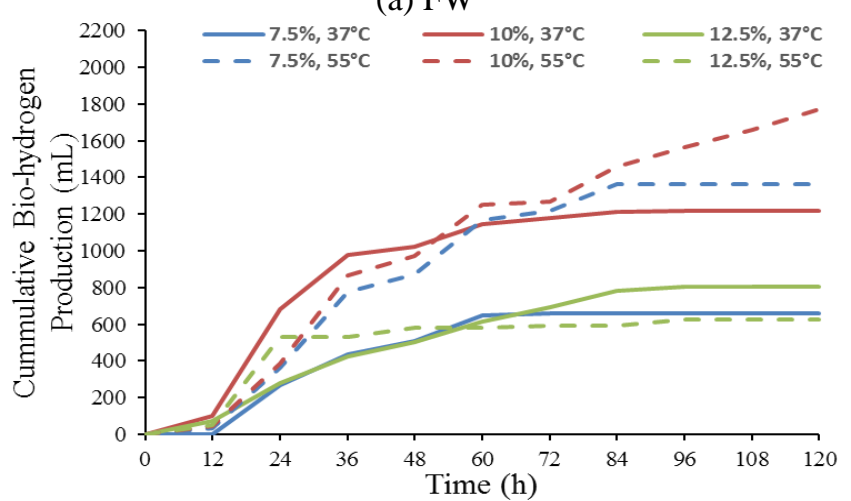

(b) NW

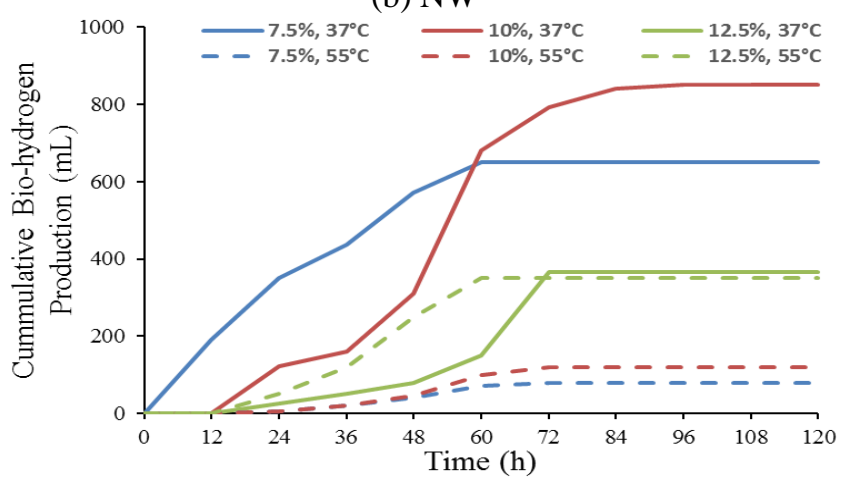

(c) RW

Figure 2. Cumulative Bio-hydrogen production from different waste under different TS concentration.

The decrease in $R_{m}$ is because of the decrease in the amount of soluble compounds due to less available water as well as increase in adsorption of nutrients to solid surface (RobledoNarváez et al., 2013). On the other hand, the reduction in cumulative bio-hydrogen production at higher TS of $12.5 \%$ was likely to associate due to shifting of acidogenic phase to solventogenic phase because of consumption of hydrogen to acids to alcohols (Ginkel et al., 2001). The increase in temperature from mesophilic to thermophilic also increased the NW cumulative bio-hydrogen production (Chaudhry et al., 2015). As a whole, the highest experimental cumulative bio-hydrogen production of $1723 \mathrm{~mL}$ was observed in $10 \% \mathrm{NW}$ digester under thermophilic conditions.

Similar effect of TS was also observed for RW under mesophilic conditions (Fig. 2c). The increase in temperature within experimental range decreased the cumulative biohydrogen production from RW digesters except $12.5 \%$ TS concentration. The RW has higher carbohydrate content (Table 1) as compared to NW and FW, which caused a negative impact of increase in temperature on bio-hydrogen production from RW as reported by Fang et al. (2006).

Most of the bio-hydrogen was produced during 24 to 60 hours of incubation as reported in previous studies (Dong et al., 2009; Liu et al., 2013). After 72 hours, hydrogen production reduced considerably to zero under mesophilic as well as thermophilic temperatures. That might be due to consumption of hydrogen consumers like homoacetogens as methanogens were deactivated initially due to thermal treatment ( $\mathrm{Oh}$ et al., 2003).

Hydrogen yield comparison: The bio-hydrogen yield is shown in Table 2. It can be observed that the $7.5 \% \mathrm{FW}$ produced 5\% more bio-hydrogen under mesophilic conditions, but the bio-hydrogen yield was increased by $26.8 \%$ which represented the efficient conversion of organic matter to bio-hydrogen. On the other hand, the highest cumulative bio-hydrogen of $1124 \mathrm{~mL}$ was observed from $12.5 \% \mathrm{FW}$ under thermophilic conditions but the highest biohydrogen yield of $60.31 \mathrm{~mL} / \mathrm{VS}_{\text {fed }}$ from $\mathrm{FW}$ was observed at $7.5 \%$ TS concentration under thermophilic conditions. Similarly, the $10 \% \mathrm{FW}$ also has higher bio-hydrogen yield as compared to $12.5 \% \mathrm{FW}$ under thermophilic conditions (Table 2 ). This represented that the efficiency of converting organic matter in term of volatile solids decreased with an increased in TS concentration within experimental range. The negative impact of increase in TS was also reported by other researchers (Motte et al., 2013; Paula N. Robledo-Narváez, 2013). At the same time, the effect of increase in temperature with in experimental increased with an increase in TS concentration of FW.

The NW also represented the similar effect of increasing TS and thermophilic $7.5 \% \mathrm{NW}$ represented the highest experimental yield of 95.8, whereas the highest experimental cumulative bio-hydrogen production of $1723 \mathrm{~mL}$ was observed by thermophilic $10 \% \mathrm{NW}$ digester. The increase in TS concentration in NW digester from 10 to $12.5 \%$ decreased the bio-hydrogen yield and cumulative bio-hydrogen production both.

The increase in TS concentration of RW from 7.5 to $10 \%$ increased the bio-hydrogen yield, but further increase in TS to $12.5 \%$ decreased the yield under mesophilic conditions. The similar impact of increasing TS was observed under thermophilic conditions except that the $12.5 \% \mathrm{RW}$ has higher bio-hydrogen yield under thermophilic conditions. As a whole, the bio-hydrogen yields obtained in the present study are in agreement with the finding of Lin et al. (2013). 
Fermentation process stability: There are many factors like $\mathrm{pH}$, alkalinity and VFA etc. that can affect the anaerobic digestion. The production of fatty acids with time caused the $\mathrm{pH}$ to reduce as well as decrease the buffering capacity of the reactor that was measured as alkalinity. The $\mathrm{pH}$ of all reactors was daily maintained at $\mathrm{pH} 7$, which was found an optimum pH in our previous study (Sattar et al., 2016) and the drop in $\mathrm{pH}$ is presented in Figure 3.

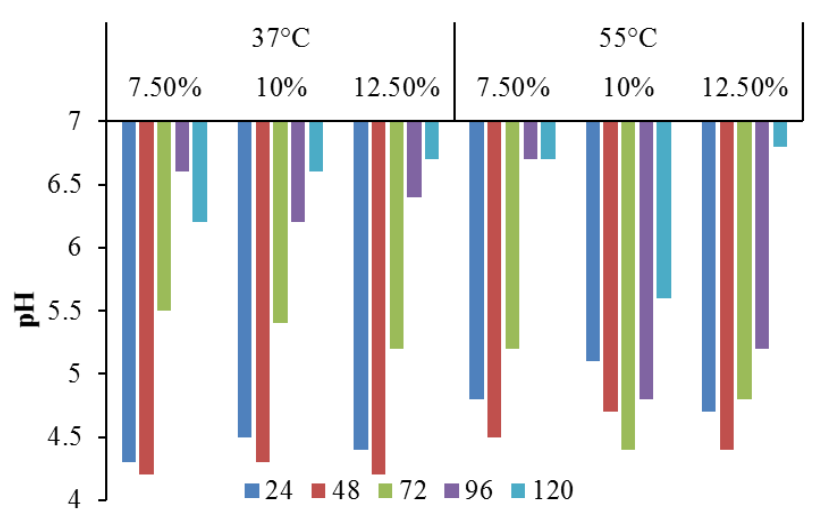

(a) FW

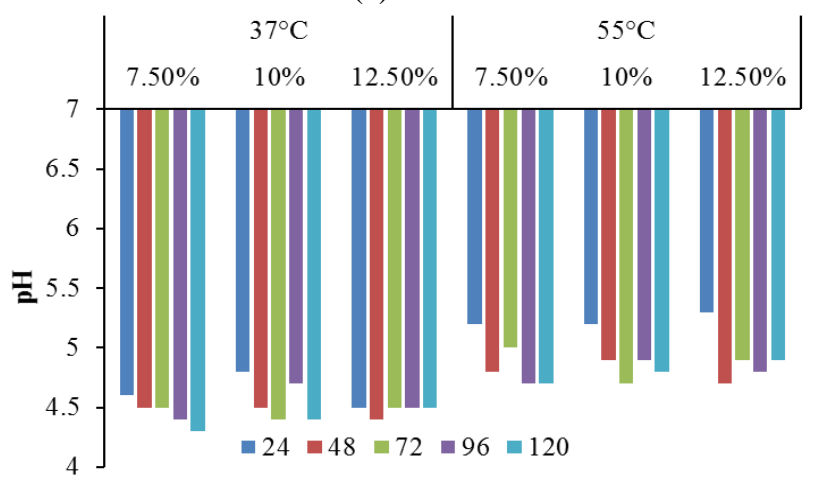

(b) NW

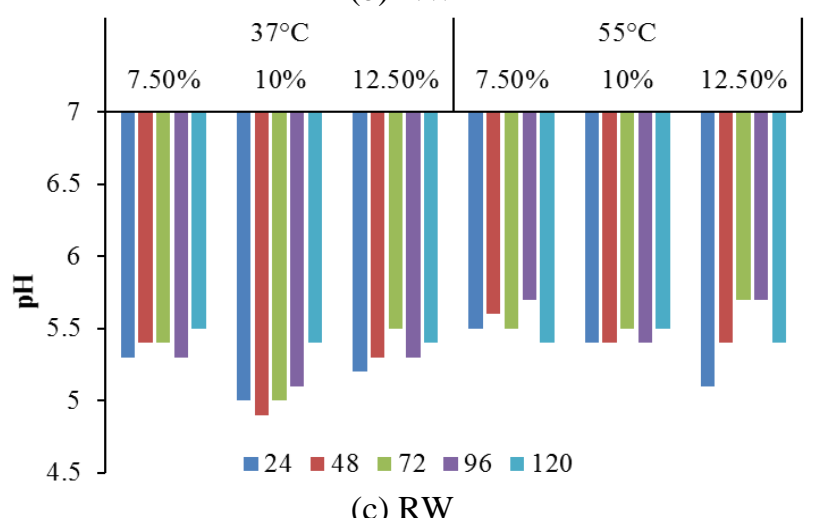

Figure 3. Effect of TS concentration and waste type on drop in $\mathrm{pH}$.

It can be observed that the drop in $\mathrm{pH}$ was high during biohydrogen production (24-48h) which was reduced as the biohydrogen production was started to decline (48-72h) in FW digesters (Fig. 2a, 3a). The intensity of drop in $\mathrm{pH}$ was further decreased when bio-hydrogen production from FW ceased as in all FW reactors. On the other end, the drop in $\mathrm{pH}$ remained higher in $10 \% \mathrm{FW}$ digester under thermophilic conditions, where the bio-hydrogen production was not ceased. As a whole, It is clear from the Figure $3 \mathrm{a}$ and $\mathrm{b}$ that the drop in $\mathrm{pH}$ under thermophilic conditions was lower than that observed under mesophilic conditions, which was also reported by Gadow et al. (2012). On the other hand, the drop in $\mathrm{pH}$ was higher in NW digesters as compared to FW digesters (Fig. 3a, $3 b$ ) as a whole due to which the bio-hydrogen production was also higher in NW digesters as observed in Table 2. The effect of temperature opposite on drop in $\mathrm{pH}$ in case of $\mathrm{NW}$ as compared to FW.

Similarly, the drop in $\mathrm{pH}$ due to increase in temperature was same in RW digesters as observed for NW digester as both are rich in carbohydrates as compared to FW. The drop in $\mathrm{pH}$ during incubation was less in RW as a whole as compared to other two tested wastes, which was in agreement with the findings of Fang et al. (2006). Alkalinity can be considered as another process stability parameter along with $\mathrm{pH}$, as $\mathrm{pH}$ cannot represent buffering capacity of the digester during incubation. The effect of TS, waste type, temperature and time on Alkalinity is presented in Figure 4. It was observed that the alkalinity increased with time as reported by Lin et al. (2013). Increase in FW alkalinity was more than under mesophilic conditions as compared to thermophilic conditions, which was in agreement with the findings of Shin et al. (2004). An abrupt increase in FW alkalinity was observed after 60 hours during which most of the biohydrogen was produced (Fig. 2a, 4a). It was also observed that the alkalinity of $10 \% \mathrm{FW}$ digester was smaller at the end of fermentation as compared to other FW TS concentrations.

The alkalinity of NW and RW was smaller than FW and remained less than $5000 \mathrm{mg} / \mathrm{L}$, representing a fermentation process as an optimum process (Ren and Wang, 2004). The increase in TS concentration in NW digesters affect the alkalinity in the same way observed for cumulative biohydrogen production i.e., increase in TS from 7.5 to $10 \%$ increased the alkalinity and further increase in TS decreased the alkalinity as observed in Figure $4 \mathrm{~b}$ and table 2. In case of $\mathrm{RW}$, the alkalinity increased with an increase in TS till 72h of incubation during which most of the bio-hydrogen was produced. The increase in temperature decreased the alkalinity of RW digesters and as a whole $12.5 \%$ TS have the high alkalinity as compared to other RW TS concentrations. An abrupt increase and decrease in alkalinity was observed during 60 to 96 hours of incubation, the same duration where bio-hydrogen production from RW ceased or reached to its minimum value. As a whole the increase in temperature decreased the alkalinity of FW and RW only. There was an abrupt change in alkalinity in all digesters after 48 to $72 \mathrm{~h}$ of incubation. 


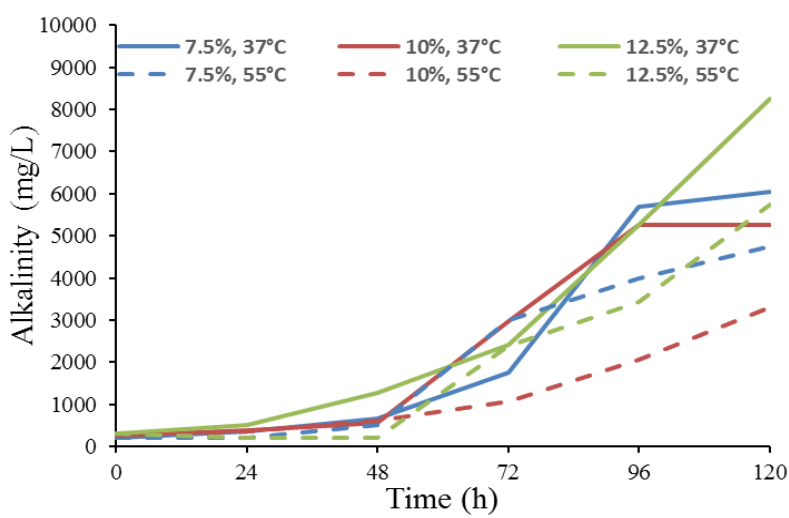

(a) FW

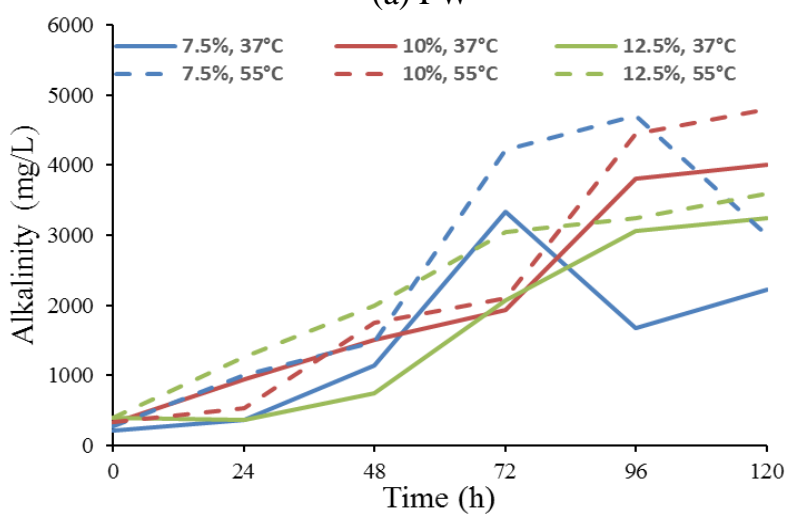

(b) NW

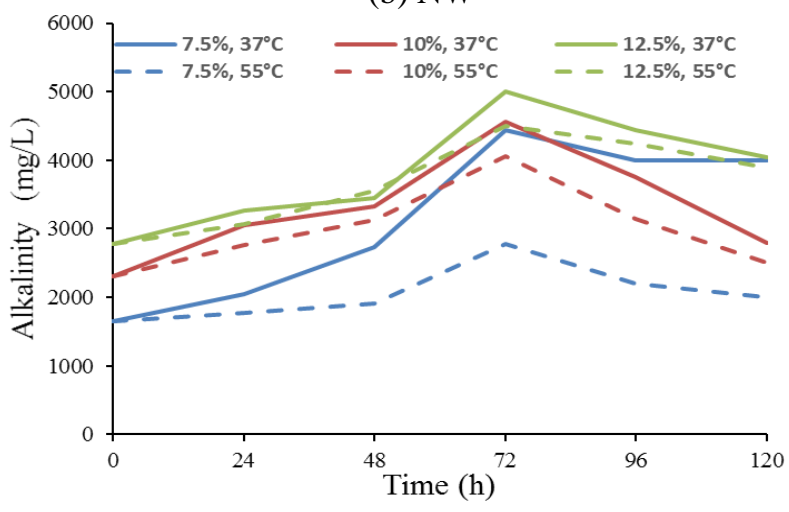

(c) RW

Figure 4. Effect of TS and temperature on Alkalinity.

The VFA is used as an indicator of biodegradable organics during the fermentation process. The effect of time and temperature on VFA is shown in Figure 5. It was observed that VFA increased with time in all digester as Clostridium mix consortia was used as seed for bio-hydrogen production (Lin et al., 2013). The VFA of FW under mesophilic conditions was higher than those at thermophilic conditions and TS 10\% FW produced the least amount of VFA as compared to other two TS levels under both temperatures (Gadow et al., 2012).

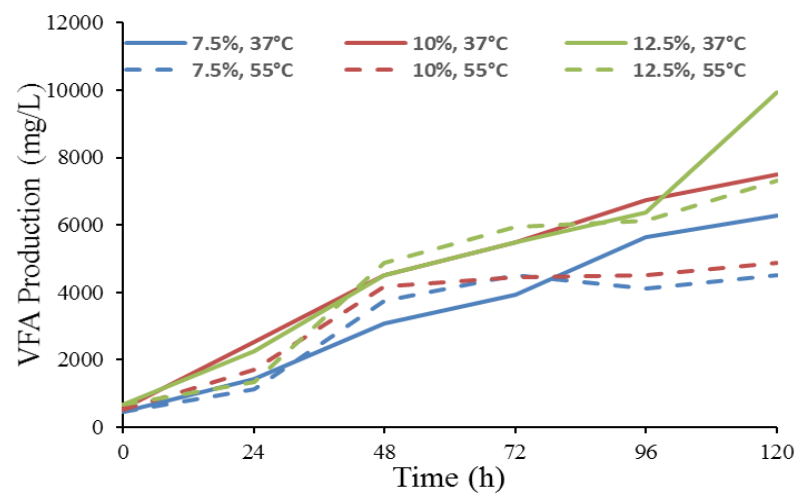

(a) FW

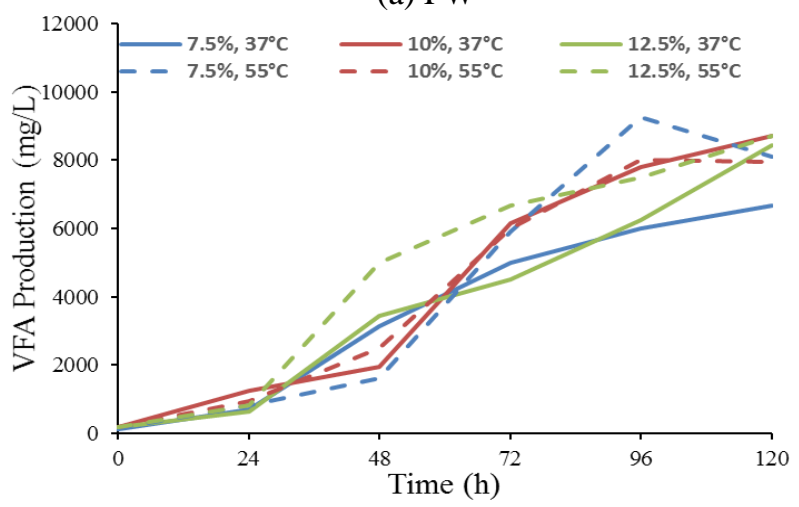

(b) NW

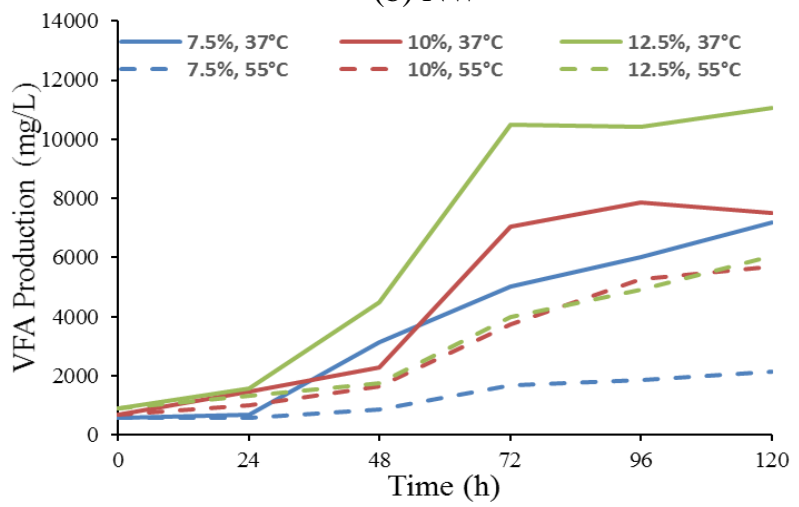

(c) RW

Figure 5. Effect of TS concentration and waste type on VFA production.

The same trend was observed for RW but the increase in VFA of RW with time and temperature was less than FW. In case of NW, the increase in temperature from mesophilic to thermophilic conditions caused an increase in VFA. The increase in VFA during active bio-hydrogen duration (2448h) was not so high that represent bio-hydrogen as main product of anaerobic digestion. The decrease in bio-hydrogen production after $72 \mathrm{~h}$ (Fig. 2) is might be conversion of glucose to VFA by homoacetogenic bacteria that reached up to such level where bio-hydrogen production was not feasible (Zhang et al., 2014). The higher concentration of VFA 
together with low $\mathrm{pH}$ can also be inhibitory to bacteria that can cause unfavourable physical changes in the cell that reduce the bio-hydrogen production. By such physical changes, excessive energy is required to pump ions and that energy can be available at higher temperature. So it increased the yield at elevated temperatures, as observed in case of $\mathrm{FW}$ and NW (Zoetemeyer RJ, 1982; Gottschalk, 1986; Switzenbaum MS, 1990).

Conclusion: The effect of initial TS concentration (7.5 to $12.5 \%$ ) on bio-hydrogen production potential on food waste (FW), noodle waste (NW)and rice waste (RW) co-digested with heat shocked sludge under mesophilic and thermophilic conditions were studied. As a whole, the increase in TS concentration from 7.5 to $10 \%$ found effective to increase the bio-hydrogen production as a whole. The $7.5 \%$ TS concentration represented the higher conversion efficiency of volatile solids to bio-hydrogen as compared to other TS concentrations as the highest experimental bio-hydrogen yield of $95.8 \mathrm{~mL} / \mathrm{VS}_{\mathrm{fed}}$ were obtained by $7.5 \% \mathrm{NW}$ digester under thermophilic conditions. Increase in temperature from mesophilic to thermophilic conditions was increased the biohydrogen production from $\mathrm{FW}$ and NW, whereas the same increase in temperature found effective mean to reduce VFA production from FW and NW. As a whole, the bio-hydrogen was mostly produce during $24-72 \mathrm{~h}$ of incubation from all waste under both tested temperatures.

Acknowledgment: The authors thank Professor Chen Kunjie for experimental support.

\section{REFERENCES}

APHA. 2005. Standard methods for the examination of water and wastewater, $25^{\text {th }}$ Ed. Washington, DC: American Public Health Association.

Chaudhry, A., A. Sattar, C. Ji, S. Sattar, K. Yousaf and S. Hashim. 2015. Optimizing the impact of temperature on bio-hydrogen production from food waste and its derivatives under no ph control using statistical modelling. BGeo. 12:6503-6514.

Chen, W.-H., S.-Y. Chen, S. Kumar Khanal and S. Sung. 2006. Kinetic study of biological hydrogen production by anaerobic fermentation. Int. J. Hydrogen Energ. 31:21702178.

Dong, L., Y. Zhenhong, S. Yongming, K. Xiaoying and Z. Yu. 2009. Hydrogen production characteristics of the organic fraction of municipal solid wastes by anaerobic mixed culture fermentation. Int. J. Hydrogen Energ. 34:812-820.

Fang, H.H., C. Li and T. Zhang. 2006. Acidophilic biohydrogen production from rice slurry. Int. J. Hydrogen Energ. 31: 683-692.
Fountoulakis, M. and T. Manios. 2009. Enhanced methane and hydrogen production from municipal solid waste and agro-industrial by-products co-digested with crude glycerol. Bioresour. Technol. 100:3043-3047.

Gadow, S., Y.-Y. Li and Y. Liu. 2012. Effect of temperature on continuous hydrogen production of cellulose. Int. J. Hydrogen Energ. 37:15465-15472.

Ginkel, S.V., S. Sung and J.-J. Lay. 2001. Biohydrogen production as a function of $\mathrm{pH}$ and substrate concentration. Environ. Sci.Technol. 35:4726-4730.

Gottschalk, G. 1986. Bacterial metabolism, $2^{\text {nd }}$ Ed. New York: Springer.

Lay, J.-J. and K.-S. Fan. 2003. Influence of chemical nature of organic wastes on their conversion to hydrogen by heat-shock digested sludge. Int. J. Hydrogen Energ. 28:1361-1367.

Li, C. and H.H. Fang. 2007. Fermentative hydrogen production from wastewater and solid wastes by mixed cultures. Crit. Rev. Environ. Sci. Technol. 37:1-39.

Li, Q. and C.-Z. Liu. 2012. Co-culture of clostridium thermocellum and clostridium thermosaccharolyticum for enhancing hydrogen production via thermophilic fermentation of cornstalk waste. Int. J. Hydrogen. Energ. 37:10648-10654.

Liaquat, R., S. Kaleem, A. Azeem, A. Jamal and M.I. Ali. 2015. Production and characterization of $\alpha$-amylase from indigenously isolated bacterial strains treating organic waste in anaerobic digester. Pak. J. Agri. Sci. 52:895903.

Lin, Y., J. Liang, S. Wu and B. Wang. 2013. Was pretreatment beneficial for more biogas in any process? Chemical pretreatment effect on hydrogen-methane co-production in a two-stage process. J. Ind. Eng. Chem. 19:316-321.

Lin, Y., S. Wu and D. Wang. 2013. Hydrogen-methane production from pulp \& paper sludge and food waste by mesophilic-thermophilic anaerobic co-digestion. Int. J. Hydrogen Energ. 38:15055-15062.

Liu, C.-M., C.-Y. Chu, W.-Y. Lee, Y.-C. Li, S.-Y. Wu and Y.-P. Chou. 2013. Biohydrogen production evaluation from rice straw hydrolysate by concentrated acid pretreatment in both batch and continuous systems. Int. J. Hydrogen. Energ. 38:15823-15829.

Lu, L., N. Ren, X. Zhao, H. Wang, D. Wu and D. Xing. 2011. Hydrogen production, methanogen inhibition and microbial community structures in psychrophilic singlechamber microbial electrolysis cells. Energ. Environ. Sci. 4:1329-1336.

Mizuno, O., M. Shinya, M.K. Suzuki, J. Yaguchi, T. Noike. 2000. Effect of $\mathrm{pH}$ on hydrogen production from noodle manufacturing wastewater. Environ. Energy Res. 37:97106.

Morimoto, M., M. Atsuko, A. Atif, M. Ngan, A. Fakhru'lRazi, S. Iyuke and A. Bakir. 2004. Biological production 
of hydrogen from glucose by natural anaerobic microflora. Int. J. Hydrogen. Energ. 29:709-713.

Motte, J.-C., E. Trably, R. Escudié, J. Hamelin, J.-P. Steyer, N. Bernet, J.-P. Delgenes and C. Dumas. 2013. Total solids content: A key parameter of metabolic pathways in dry anaerobic digestion. Biotechnology for Biofuels 6: 19. DOI 10.1186/1754-6834-6-164.

Nabi, N.G., M. Asghar, A. Shah, M. Sheikh and M. Asad. 2003. Production of pectinase by trichoderma harzianum in solid state fermentation of citrus peels. Pak. J. Agri. Sci. 40:193-201.

Nathao, C., U. Sirisukpoka and N. Pisutpaisal. 2013. Production of hydrogen and methane by one and two stage fermentation of food waste. Int. J. Hydrogen Energ. 38:15764-15769.

Oh, S.-E., S. Van Ginkel and B.E. Logan. 2003. The relative effectiveness of ph control and heat treatment for enhancing biohydrogen gas production. Environ. Sci. Technol. 37:5186-5190.

Paula N.R.N., M.M.P. Karla, M. Hector, V. Poggi, R.L. Elvira, C.C. Graciano, O.C. Alfredo, R.S. Noemi, E.V. Carlos, P.N. Teresa and S.M. Alfredo. 2013. The influence of total solids content and initial ph on batch biohydrogen production by solid substrate fermentation of agroindustrial wastes. J. Environ. Manage. 128:126137.

Pisutpaisal, N. and S. Hoasagul. 2012. Kinetics of biohydrogen production from ozonated palm oil mill effluent using c. Butyricum and c. Acetobutylicum coculture. Adv. Mater. Res. 512:1515-1519.

Ramos, C., G. Buitrón, I. Moreno-Andrade and R. Chamy. 2012. Effect of the initial total solids concentration and initial ph on the bio-hydrogen production from cafeteria food waste. Int. J. Hydrogen Energ. 37:13288-13295.

Ren, N. and A. Wang. 2004. The method and technology of anaerobic digestion. Chem. Ind., Beijing.

Reungsang, A., C. Sreela-or and P. Plangklang. 2013. Nonsterile bio-hydrogen fermentation from food waste in a continuous stirred tank reactor (cstr): Performance and population analysis. Int. J. Hydrogen Energ. 38:1563015637.

Robledo-Narváez, P.N., K.M. Muñoz-Páez, H.M. PoggiVaraldo, E. Ríos-Leal, G. Calva-Calva, L.A. OrtegaClemente, N. Rinderknecht-Seijas, C. Estrada-Vázquez, M.T. Ponce-Noyola and J.A. Salazar-Montoya. 2013. The influence of total solids content and initial ph on batch biohydrogen production by solid substrate fermentation of agroindustrial wastes. J. Environ. Manage.128:126-137.
Saraphirom, P. and A. Reungsang. 2010. Optimization of biohydrogen production from sweet sorghum syrup using statistical methods. Int. J. Hydrog. Energy 35:1343513444.

Saripan, A.F. and A. Reungsang. 2014. Simultaneous saccharification and fermentation of cellulose for biohydrogen production by anaerobic mixed cultures in elephant dung. Int. J. Hydrogen Energ. 39:9028-9035.

Sattar, A., C. Arslan, C. Ji, K. Chen, A. Nasir, H. Fang and M. Umair. 2016. Optimizing the physical parameters for bio-hydrogen production from food waste co-digested with mixed consortia of clostridium. J. Renew. Sustain. Energy 8:013107.

Sattar, A., C. Arslan, C. Ji, S. Sattar, I. Mari, H. Rashid and F. Ilyas. 2016. Comparing the bio-hydrogen production potential of pretreated rice straw co-digested with seeded sludge using an anaerobic bioreactor under mesophilic thermophilic conditions. Energies 9:198.

Shin, H.-S., J.-H. Youn and S.-H. Kim. 2004. Hydrogen production from food waste in anaerobic mesophilic and thermophilic acidogenesis. Int. J. Hydrogen Energ. 29:1355-1363.

Shiwei, X. 2005. Analysis of china food consumption and waste (in chinese). Food Nutr. China 11:4-8.

Sreela-or, C., T. Imai, P. Plangklang and A. Reungsang. 2011. Optimization of key factors affecting hydrogen production from food waste by anaerobic mixed cultures. Int. J. Hydrogen Energ. 36:14120-14133.

Switzenbaum, M.S., G.E. Giraldo and R.F. Hickey. 1990. Monitoring of the anaerobic methane fermentation process. Enzyme microbial technology. Enzym. Microb. Technol. 12:722-730.

Tai, J., W. Zhang, Y. Che and D. Feng. 2011. Municipal solid waste source-separated collection in China: A comparative analysis. Waste Manage. 31:1673-1682.

Wang, L., S.Cheng, Q. Li and X. Zengrang. 2013. Tourist dining behavior in lhasa city (in chinese). Resour. Sci. 35:848-857.

Zhang, L., Q. Ban, J. Li and Y. Xu. 2014. Assessment of effects of yeast extract on bio-hydrogen production from anaerobic activated sludge. Int. J. Agric. Biol. 16:11891193.

Zhu, H., W. Parker, R. Basnar, A. Proracki, P. Falletta, M. Béland and P. Seto. 2008. Biohydrogen production by anaerobic co-digestion of municipal food waste and sewage sludges. Int. J. Hydrogen Energ. 33:3651-3659.

Zoetemeyer, R.J., A.J.C.M. Mathijsen, A. Cohen and C. Boelhouwer. 1982. Product inhibition in the acid forming stage of the anaerobic digestion process. Water Res. 16:633-639. 